\title{
A motivação missionária religiosa dos profissionais das unidades de acolhimento para jovens: problema ou solução?*
}

\section{The professional missionary motivation in the shelters for the youth: problem or solution?}

\author{
Daniel Gonçalves Alves ${ }^{1}$, Adriana Abreu Lemos², Mayara C. Muniz \\ Bastos Moraes ${ }^{3}$, Elizabeth Espindola Halpern ${ }^{4}$, Ligia Costa Leite ${ }^{5}$
}

\begin{abstract}
ALVES, D. G.; LEMOS, A. A.; MORAES, M. C. M. B.; HALPERN, E. E.; LEITE, L. C. A motivação missionária religiosa dos profissionais das unidades de acolhimento para jovens: problema ou solução? Rev. Ter. Ocup. Univ. São Paulo, v. 23, n. 2, p. 137-145, maio/ago. 2012.

RESUMO: O estudo examina em que medida a motivação missionária representa um problema ou uma solução para os profissionais que atuam nas Unidades de Acolhimento para jovens de uma rede Municipal. O trabalho se ancorou nos resultados oriundos de um projeto feito, entre 2008 e 2010, em dois abrigos localizados no Rio de Janeiro, realizando 47 entrevistas com profissionais em diferentes funções. O método empregado para a coleta de dados foi o da história oral, utilizando um roteiro de entrevistas semi-estruturado. A análise baseou-se na teoria da comunicação, abduzindo categorias a partir das narrativas. Constatou-se que um número significativo de cuidadores demonstrou que suas crenças religiosas parecem nortear a atuação no abrigo, a fim de minimizar o sofrimento psíquico. Concluiu-se que a motivação missionária desses profissionais possui significados diversos, sobretudo indica a falta de capacitação e supervisão.
\end{abstract}

DESCRITORES: Abrigo; Prática profissional; Religião; Adolescente institucionalizado, Saúde mental; Cuidadores; Motivação.

\footnotetext{
* Este artigo é um dos resultados do estudo Violência, Juventude e Saúde Mental, parte do Projeto de Pesquisa Evasão escolar, drogas, criminalidade: os descaminhos na adolescência e suas articulações com questões do sujeito, realizado pelo Instituto de Psiquiatria/UFRJ, entre 2008-2010, com suporte financeiro do CNPq.

1. Aluno de Graduação de Psicologia do Centro Universitário Augusto Motta, bolsista de Iniciação Científica IC-PIBIC/CNPQ.

2. Aluna de Graduação em Psicologia da Universidade Federal do Rio de Janeiro, bolsista IC-FAPERJ.

3. Aluna de Graduação em Psicologia da Universidade Estácio de Sá, bolsista IC-FAPERJ

4. Doutoranda do Programa de Pós-Graduação em Psiquiatria e Saúde Mental - Universidade Federal do Rio de Janeiro - IPUB/UFRJ.

5. Professora da pós-graduação IPUB-UFRJ.

Endereço para correspondência: Rua Vinte Oito de Outubro, nº 20, Tauá, Ilha do Governador. Rio de Janeiro, RJ. CEP 21910-510. e-mail: danielalvesdga@gmail.com
} 


\section{INTRODUÇÃO}

A o examinar a trajetória da questão do acolhimento institucional de jovens, desde o Brasil colonial, observou-se que as instituições religiosas participaram ativamente desse processo. Inclusive, as leis relacionadas às crianças abandonadas eram baseadas nos ideais europeus e apoiadas pelas práticas assistencialistas da Igreja Católica. Após a República, o Estado, então laico, assumiu a responsabilidade pelas necessidades sociais da população, apesar do papel da Igreja continuar ativo.

A intensa participação das entidades religiosas indica a presença de uma Motivação Missionária, aqui denominada (MM), junto aos desvalidos. Esse aspecto parece ter subsistido no íntimo e na prática laboral de muitos profissionais, que atuam hoje nas Unidades de Acolhimento (UAs) da Rede de Proteção Especial para jovens, da Secretaria Municipal de Assistência Social (SMAS) do Rio de Janeiro. O objetivo da rede é acolher jovens em situação de risco, como uma medida protetiva definida pelo Estatuto da Criança e do Adolescente (ECA), no artigo 101 (BRASIL, 1990).

A experiência religiosa está presente na história da humanidade de diferentes formas, em diversas culturas e sociedades. Porém, não é a intenção deste trabalho discorrer sobre o tema da religião, mas alcançar como e por que ela emerge dentro de um determinado contexto e no dia-a-dia dos profissionais das UAs.

Por este tema ser delicado, é preciso fazer um esclarecimento preliminar sobre o significado da MM ao longo deste estudo. A análise sobre a MM não pretende se ater a uma corrente religiosa específica, mas ao impulso de indivíduos em propagar a fé e os valores que consideram positivos, norteando a atuação profissional nos abrigos por suas crenças religiosas.

Visando compreender a dinâmica do cotidiano dos cuidadores que trabalham em abrigos, partiu-se de uma escuta sobre suas experiências laborativas e do impacto destas na sua saúde mental.

Para tal, o projeto de pesquisa Violência, Juventude e Saúde Mental do Instituto de Psiquiatria da Universidade Federal do Rio de Janeiro (IPUB/UFRJ), finalizado em 2010, coletou narrativas de profissionais das UAs, a fim de observar como as diferentes formas de violência se expressam nesse ambiente. Em continuidade, propor intervenções intersetoriais, utilizando-se as técnicas da reabilitação psicossocial, capazes de mediar às relações entre os profissionais, assim como as deles com os jovens.

Para tanto, procurou-se capacitar os cuidadores na abordagem da reabilitação psicossocial (PITTA, 1996; SARACENO, 1999), que embora não seja objeto de discussão neste artigo, foi uma estratégia essencial no desenvolvimento do projeto de pesquisa. Essa capacitação propiciou que os profissionais pudessem multiplicar as ações juntamente com os jovens abrigados, que vivem em permanente risco de desafiliação (CASTEL, 1998) e, em alguns casos, refletir sobre a prática da MM.

O presente artigo é parte dos resultados obtidos na pesquisa e tem por objetivo investigar em que medida a MM representa um problema ou uma solução na atuação profissional.

\section{PROCEDIMENTOS METODOLÓGICOS}

A pesquisa foi aprovada pelo Comitê de Ética em Pesquisa do IPUB/UFRJ em 2006, $\mathrm{n}^{\circ}$ 0008.0.249.000-06, e financiada pelo CNPq no período de 2008 a 2010. Todos entrevistados assinaram um Termo de Consentimento livre e esclarecido e seus nomes e o das UAs foram omitidos para garantir a confidencialidade.

Realizou-se 47 entrevistas individuais com profissionais de diferentes funções (assistente social, psicóloga, educadores, serviços de apoio), em duas UAs. Para isso, utilizou-se a história oral como método para coleta de dados, a partir de um instrumento - um roteiro semi-estruturado de entrevistas - para que cada profissional narrasse sua trajetória nos aspectos da saúde mental e na relação com as UAs, colegas de equipe, jovens e outras instituições.

A escolha da história oral justifica-se, segundo definição de Ferreira e Amado (1996), porque:

[Ela] estabelece e ordena procedimentos de trabalho - tais como os diversos tipos de entrevistas e as implicações de cada um deles para a pesquisa, as várias possibilidades de transcrição de depoimentos, suas vantagens e desvantagens, as diferentes maneiras de o historiador relacionar-se com seus entrevistados sobre seu trabalho [...] ela funciona como ponte entre teoria e prática. (p.xvi)

Por outro lado, testemunhos orais podem permitir que cada entrevistado recorde e exponha questões importantes, dando legitimidade e historicidade às suas vozes (THOMPSON, 1992). Esse método ainda permite obter conhecimentos novos com base em fontes inéditas, auxiliando os indivíduos a se situarem como sujeitos de suas vidas (LOZANO, 2006). Enfim, entendendo como Alberti (2004), entrevistas de história oral podem revelar padrões 
de socialização e trajetórias comuns em um grupo, expondo partes de cada vivência, concebido por quem viveu. Enfim, a história oral traz uma dimensão técnica e teórica, sendo "capaz apenas de suscitar, jamais de solucionar, questões; [ela] formula as perguntas, porém não oferece as respostas" (FERREIRA; AMADO, 1996, p.xvi).

Deste modo, a história oral realçou, nesta pesquisa, elementos e informações comuns dos narradores que suscitaram categorias de análise.

Para análise e discussão das informações coletadas, empregou-se a Teoria da Comunicação, mais precisamente o método da abdução (BOUDON, 1998), que implica trazer à tona novos elementos a serem examinados. Diferentemente de outros métodos, este não trabalha com categorias préestabelecidas, mas as define a partir da abdução do material colhido no campo.

Para início do tratamento dos dados, induz-se um tema, baseado nele deduz-se uma hipótese, que irá delimitar as categorias-base, e finalmente, abduzem-se pistas para análise. A partir daí vai se tecendo uma "rede de sentidos" que se cruza com outras pistas, tornando explícito o que antes estava implícito e revelando novos fatos. A verificação desses elementos permite o surgimento de novos argumentos: a tese e a antítese que, por fim, vão gerar uma síntese da análise de cada diagrama, denominado templum, comprovando ou não a hipótese inicial. Assim, os temas são analisados por uma alternância argumentativa (BOUDON, 1998). A categoria-base é mediatizada por duas meta-categorias: uma positiva e outra negativa. A Figura 1 é o templum modelo de como foi feita a análise dos dados que será apresentada nos resultados.

A MM se destacou como padrão e trajetória comum no grupo pesquisado e será a categoria base que perpassa os resultados apresentados neste artigo.

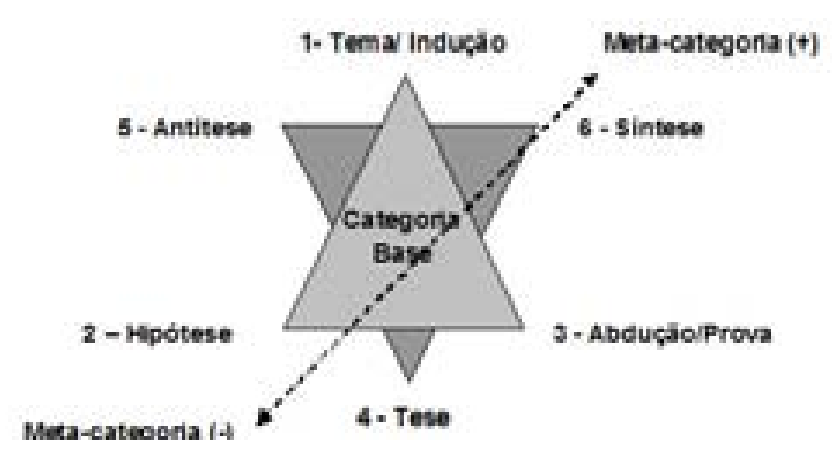

Figura 1 - Diagrama-síntese correspondente à análise dos dados

\section{RESULTADOS E DISCUSSÃO}

Sabe-se, historicamente, que no âmbito da assistência social a religiosidade exerce grande influência em contextos institucionais, inclusive entre os profissionais (NEVES et al., 2007; SIMÕES, 2005; VALLA, 2000; VASCONCELOS et al., 2009). Apesar de esta ser uma realidade já discutida e conhecida, essas análises não repercutiram em mudanças nesse quadro. Assim, para avaliar em que medida a MM possa ser um problema ou uma solução no trabalho em abrigos, é importante compreender os seus significados a partir da voz dos entrevistados. Abaixo, serão apresentados fragmentos das narrativas que exemplificam as análises da categoria base (MM), divididos em três tópicos.

\section{Motivação missionária (MM) e a assistência social}

A MM faz parte do dia-a-dia de muitos profissionais dos abrigos. Mais do que julgá-la, conjurá-la ou reprimi-la, é preciso entender seus significados e seus efeitos, sobretudo no binômio: assistência social/assistencialismo.

Fidelis (2005) distinguiu a diferença entre os termos assistência e assistencialismo, no que dizia respeito às essas práticas. A assistência social dirige suas ações na perspectiva de garantia de direitos sociais, numa condição de política pública. Em contrapartida, o assistencialismo foi caracterizado pela ajuda momentânea e caridosa às camadas sociais menos favorecidas, não ajudando a emancipar os beneficiados e reforçando sua condição de dependência aos serviços sociais.

Neste estudo foi possível perceber que ainda havia alguns aspectos assistencialistas nas UAs e que o cotidiano do acolhimento se encontrava sutilmente movido e sustentado pela MM, em vários trabalhadores. Estes buscavam amparo na religião, oscilando entre a assistência social e o assistencialismo, especialmente quando se viam diante de desafios e obstáculos.

Observou-se que existia uma correlação entre a prática assistencialista e o maior uso da $\mathrm{MM}$, o que acabava não ajudando o jovem a fazer as suas escolhas, a pensar sobre si mesmo, seus projetos de vida e suas tendências religiosas ou de outra ordem:

A gente procura mostrar o melhor caminho pra eles. Procuro sempre estar buscando um ou outro [jovem para conversar]. Às vezes, chamo dois, três, converso com eles, mostrando o caminho ideal pra que eles saiam da droga, busquem uma religião. E a gente vai passando alguma coisa que a gente sabe de bom pra eles. (Porteiro). 
Em contrapartida, o uso menor da MM abria espaço para o exercício da assistência social, onde o jovem seria sujeito no processo de educação social e haveria isenção do compromisso de propagar valores pessoais, o oposto ao relatado abaixo:

Pela minha experiência, eu acho que devo ensinar a alguém. Se eu estou aqui não é por acaso. Esses meninos especiais precisam de mim. Eu sou Evangélica, a minha religião me ajuda porque a paciência, a tranquilidade é superimportante para passar para esses meninos que estão lidando com drogas e dispersos da família. Você passa tranquilidade quando é necessário. (Educadora).

Muitos profissionais, impulsionados pelos ideais de solidariedade e de fraternidade, com pouca clareza de quais eram suas funções nos abrigos, aceitavam esse emprego, sem saber a complexidade do público que iriam acolher. Diante da ausência de informação e de formação específica, assumiam a tarefa de cuidar e de educar como parte de sua missão religiosa.

Por isso, a hipótese desse tópico foi de que, a MM era um fator motivador para o cumprimento das tarefas $\mathrm{e}$ para permanência dos profissionais na UA, mesmo com remuneração abaixo do salário mínimo, atraso no pagamento e ausência de benefícios sociais, conforme constatado nas entrevistas. Essa falta de reconhecimento profissional foi um padrão comum:

O que falta aqui é o reconhecimento do educador, que é o resto do resto pra Prefeitura. $O$ nosso salário: 400 e poucos reais. Outra coisa que a gente não tem é periculosidade ou insalubridade. Aí, você pega um adolescente aqui com tuberculose, com HIV! Pega adolescente com pneumonia, com sarna! E nós nunca pegamos nada! Até nisso o "papai do céu" protege a gente. (Educador).

A religiosidade costumava ser bastante utilizada para enfrentar essas dificuldades:

Têm dias que chego em casa e sabe qual é a vontade? Vou dar um "bico" nessa porra toda [abandonar]! Não quero mais saber disso! É um trabalho ingrato, tu não cresce em nada, não resolve nada. Mas, por outro lado, existe aqui uma coisa espiritual, já que eu sou espirita. Tenho que ficar um pouquinho mais. Você tem que ter outra visão da vida. Eu acredito que o amanhã vai melhorar. (Educador).

Lotufo Neto (1997) afirmou que a orientação religiosa na vida do indivíduo podia trazer benefícios à sua saúde mental, aqui entendida não apenas como a ausência de transtornos psiquiátricos. Para a OMS (2002) o conceito de saúde mental envolveria os seguintes fatores: bem estar subjetivo, auto-eficácia percebida, autonomia, competência, auto-realização de potencial intelectual e emocional da pessoa. A narrativa abaixo confirmou essa possibilidade, colocando a MM como fator primordial de realização:

Hoje o meu salário aqui é $R \$ 495,00$. Eu não tenho assim tanta 'esquentação de cabeça' [preocupação], como eu tinha antes [em outro emprego, onde ganhava mais]. Isso é pela religião. Não sei, parece que o pouco com Deus é muito! (Educador).

Desse modo, esses profissionais constituem um grupo-alvo que demandam ações em saúde mental, por estarem expostos à desvalorização social, vivenciada pelas situações de precarização do trabalho e vulnerabilidade relacional.

Outra questão importante a ser tratada referiu-se ao envolvimento emocional dos profissionais com os jovens abrigados. De fato, esse grupo trazia evidentes carências afetivas, aspecto que poderia ajudar a despertar nos cuidadores, sentimentos paternalistas e ações assistencialistas que se sobrepunham às suas funções e papéis estritamente profissionais.

O documento de Orientações Técnicas: Serviços de Acolhimento para Crianças e Adolescentes (BRASIL, 2009) norteia que o serviço de acolhimento não deve ter a pretensão de ocupar o lugar da família do abrigado, mas de contribuir para o fortalecimento dos vínculos familiares, favorecendo sempre que possível o processo de reintegração familiar.

Contudo, pôde-se perceber que alguns profissionais assumiam o papel de substituto paterno: "Eu vejo assim! Eu trato eles como se fosse um filho meu. A gente quer o quê para os nossos filhos? O melhor!" (Assistente Social).

A MM também era capaz de servir de estímulo para que os profissionais atuassem dessa forma, por serem despertados a sentimentos de compaixão. $\mathrm{O}$ trabalho era encarado por muitos a partir de sentimentos de caridade e de dó, como uma "boa ação" (NEVES et al., 2007).

A fala do educador a seguir demonstrou como ele lidava com os jovens abrigados, misturando a esfera do trabalho com sua vida privada, levando suas atribuições a transcenderem às profissionais:

Eu tenho eles mais como meus filhos. Eu me apeguei a eles de tal maneira que eu trato eles igual a meus filhos. Eu levo eles lá para casa, a gente faz churrasco. Eu sou evangélico, por isso, eu levo eles 
pra igreja. (...) Eu pego a Kombi, levo 10, 12, os especiais, vai todo mundo, não tenho discriminação. Quando eu não levo, minha própria filhinha de quatro anos pergunta: "Cadê meus irmãos?" Minha esposa, hoje, já ligou e falou: "Ó, traz os garotos sábado!" Sábado, eu acho que tem o bolinho dela. Já avisei, sábado vai todo mundo, apesar de estar de folga. Ai, eu venho buscar. (Educador).

A MM tornava-se o fundamento do trabalho para muitos cuidadores, pois era embasada nos valores que dizia respeito ao amor ao próximo, à vontade de promover as condições sociais de indivíduos com múltiplas carências e à difusão de crenças religiosas. Essa era uma opção plausível quando se percebia que o profissional, tecnicamente desamparado, precisava fazer uso de seus recursos pessoais para continuar nas UAs.

O exercício da profissão no abrigo era uma experiência que transcendia a prática cotidiana, transformando-se em uma missão, adotada em suas atribuições profissionais: "Mas a gente tá aqui porque a gente tem uma missão também. Às vezes, eu acho que, no fundo, no fundo, Deus tinha uma missão pra mim: 'sua missão é essa!'[reproduzindo a fala de Deus]". (Educador).

Adicionalmente, a MM podia ser uma forma de resgate e salvação:

Se você não procurar se aproximar deles, ter um grau de amizade grande pra eles confiarem em você, você não vai conseguir "arrancar" nada deles. E, se você conseguir "arrancar" o que você precisa no fundo deles, naquele miolinho do fundo do coraçãozinho deles, você consegue trabalhar bem com o que restar desse menino. (Educador).

Outra atitude era o caráter interventivo, de cunho missionário, presente nos relatos. Alguns profissionais imaginavam que a sua atuação era uma resposta a uma espécie de "chamado". Muitos acreditavam que foram predestinados a exercerem essa função, como uma "vocação" que ia além do exercício "mundano" da profissão, sendo uma atribuição divina:

Com certeza a religião interfere! Eu sou espirita há 16 anos. Recebi uma psicografia me falando desse trabalho, antes d'eu entrar pra ele, que eu trabalharia com crianças em situação de rua, na assistência. Eu tenho uma psicografia de oito páginas, muito linda, que se você lê você chora! Eu entendi que eu tinha um compromisso com essa população. (Assistente social).

Simões Neto (2005) afirmou que certas práticas assistenciais podiam ser permeadas por valores religiosos e esses valores se mostravam relevantes na busca e escolha de uma profissão. Isso podia colaborar para que muitos utilizassem vivências espiritualizadas para continuar a exercer funções complexas.

No entanto, a MM não seria apenas o atendimento a um "chamado", mas acionada em resposta aos desafios, uma trajetória comum a esse grupo de entrevistados:

A religião me ajuda bastante. Você fica mais calma, tem mais conhecimento pra lidar com cada situação.

Por que eu tenho a ajuda assim, das pastoras da igreja que eu frequento. Então, ali eu vejo que é bom pra mim, aí eu ouço e tento passar para outras pessoas. (Cozinheira).

Pela ausência de supervisão clínica e suporte técnico, que deveriam ser oferecidas pela rede de assistência social, a cozinheira acabava encontrando conforto nos aconselhamentos pastorais.

Como síntese, percebeu-se que a MM era uma forma individual de manejar os riscos à saúde mental, presentes no sofrimento psíquico, na angústia e nos sentimentos de impotência. Além da motivação redentora, do ponto de vista estritamente religioso, conscientemente ou não, esses profissionais pareciam buscar amparo em princípios e crenças religiosas, como uma estratégia de preservação da própria saúde mental.

\section{Motivação Missionária (MM): uma estratégia para minimizar o sofrimento psíquico}

As narrativas evidenciaram que os profissionais dos abrigos estavam sujeitos a diversas situações que lhes causavam desgaste psíquico, fazendo com que buscassem apoio em seus recursos e crenças religiosas. Acreditavam que a MM podia ajudar a lidar com a agressividade, camuflar a angústia e a incapacidade em ter respostas às dificuldades advindas das vivências desafiadoras do meio laboral. Assim, a MM tornava-se uma estratégia inconsciente, para minimizar o sofrimento psíquico e a ambivalência entre se sentir impotente/onipotente, quanto à sua vontade de "salvar" os jovens. Dejours (2006) confirmou que indivíduos criam defesas sutis, engenhosas, diversas e criativas contra sofrimentos padecidos no trabalho. A próxima narrativa assegura isso:

Sou católica. A religião, para mim colabora. Não 
é só o fato de um senso, é uma prática mesmo. $O$ meditar ajuda você a se concentrar. Imagina se não meditasse? Eu já teria batido em alguém. A religião faz você ter essa atitude: ver além. (Assistente Social).

Além de poder fazer uso desses recursos para se esquivar de situações desconfortáveis, a MM parecia aumentar o grau de tolerância diante das dificuldades nas relações no serviço, favorecendo um contato mais fraterno, pessoal e direto com o jovem, de forma menos mecanizada e impessoal:

Acho que eu procuro proporcionar para as pessoas o melhor possivel, não só para os meninos, mas para todos. Eu acredito muito em Deus. Eu acredito que eu posso fazer o bem para o próximo para poder eu ter o melhor. A religião me ajuda muito. Porque eu acho que o que eu quero para mim, eu tenho que fazer para os outros também. Mesmo que essa pessoa não seja tão legal comigo, mas eu vou fazer o melhor pra ela. (Pedagoga).

O próximo relato ilustrou a MM como um recurso para superar os desafios do cotidiano:

Sou católico e me apego muito na minha religião. Consigo superar até alguns desaforos, devido a ela. Porque ali a gente tem que perdoar para ser perdoado. É ai que a religião me ajuda bastante. Porque se você quer o bem, você tem que fazer o bem. Não pode vir trabalhar com a cabeça cheia de maldade. Tem que estar com a mente sempre limpa, o coração sempre puro e sem sequela. (Educador).

Por meio desse relato, foi possível observar como a religião era uma estratégia para lidar com sentimentos ambivalentes e angustiantes. De fato, não cabia julgar se essa forma era adequada ou não.

A MM surgia pela falta de uma maior qualificação para o exercício das atribuições, ou seja, do real papel de cuidar/assistir. Em decorrência, muitos tendiam a se apoiar em suas experiências religiosas. Constatou-se, pelas narrativas, a existência de uma mistura das diferentes funções: educacional/paterna/missionária:

Acho que essa relação fica um pouco até de pai pra filho. Até falo um pouco disso, porque não dá pra ser pai de todo mundo aqui. Então, eu sou só quando eu vou dar bronca neles que eu digo a mesma coisa. Então, eu acho que é isso, essa relação é amizade. (Educador).
Investimentos naqueles que convivem diretamente com os jovens "rejeitados" pela sociedade, podem trazer benefícios inequívocos a todos, sejam eles adolescentes, cuidadores ou a população externa ao mundo dos abrigos. A necessidade de capacitação dos profissionais para seu ofício é um tema abordado nas diretrizes oficiais (BRASIL, 2009), que alertam que não basta ter apenas "espírito de solidariedade", "afeto" e "boa vontade", mas um conhecimento técnico adequado. Para tanto, é importante que seja oferecida uma capacitação inicial de qualidade, formação continuada e supervisão clínica da prática. Sobretudo, cabe ao profissional estar preparado para lidar com o jovem, incluindo sua família, sabendo que ele é fruto de uma intricada rede de relações sociais e inserido em um determinado contexto cultural e econômico. O cuidador precisa desenvolver a capacidade de compreender suas peculiaridades, possibilidades e limitações, desejos e temores.

No entanto, foi possível constatar nas narrativas que a tarefa nos abrigos é de extrema complexidade, exigindo de qualquer profissional muito mais do que um curso formal poderia oferecer. Na prática, esses enfrentavam uma realidade que requeria apoio permanente e qualificado, na forma de reuniões periódicas e supervisões clínicas, que englobariam não apenas aspectos psíquicos, mas as demais questões que os desafiavam no cotidiano de trabalho.

Dentre os desafios comuns e altamente mobilizantes, destacavam-se a falta de valorização profissional (demonstrada pela baixa remuneração e atraso dessa) e, sobretudo, pelos comportamentos de rejeição e menosprezo dos jovens, os quais reproduziam nos cuidadores o que recebiam da sociedade:

Eu acredito que minha religião contribui para minha calma e meu conhecimento. Você tem que ser muito paciente, porque têm uns meninos, às vezes, que te tira do sério. Dá quase vontade de chorar. É que eles, às vezes, te roubam, te ofendem. Então, você tem que ter paciência para lidar com aquela situação. Tem que ter muita paciência, calma, para lidar com muito tipo de meninos diferentes. Porque se você tá aqui, tá aqui para ajudar eles. (Cozinheira).

Aqueles que não se utilizavam da MM, acabavam se identificando com os jovens que acolhiam, sentindo-se ainda mais desvalorizados:

As vezes a gente procede [chamar a polícia] com os meninos, um bate no outro, machuca de tirar sangue. A gente chama pra conversar, mas chega num limite. A gente leva pra DPCA [Delegacia de 
Proteção a Criança e Adolescentes]. Às vezes o delegado olha pra nossa cara, a gente com essa camisa cor de laranja, eles dão gargalhada, ou eles falam "ah não, não vou ficar com esse menino aqui não!". Muitas vezes a gente é obrigado a voltar com eles. Aonde fica a nossa moral? Ele nem registra a queixa! (Educador).

Os desafios diários nos abrigos eram múltiplos, difíceis e imprevisíveis, não podendo ser esgotados por orientações contidas em um guia ou documento normativo (BRASIL, 2009). Em síntese, os profissionais dos abrigos pareciam se apoiar em suas crenças religiosas por não existir uma habilitação e um suporte adequado para o trabalho no abrigo.

\section{aos profissionais \\ MM na Rede de Abrigos: a ausência de suporte}

Considerando que o objetivo deste estudo foi investigar em que medida a MM nos abrigos representaria um problema ou uma solução na atuação dos profissionais, esta categoria examinou a formação, a capacitação e a supervisão desses.

A hipótese formulada foi de que a ausência desse suporte pode levar ao exercício da MM, fazendo com que o profissional recorresse às suas experiências e convicções religiosas: "Eu sou evangélico. Sou pentecostal. A minha religião me ajuda, com certeza! Jesus Cristo ajuda. Trago sempre alguma coisa da minha religiosidade pra cá. Trago a minha tranquilidade, serenidade, paciência e sabedoria." (Educador) Outro reitera: "Eu sou católica, eu vou à igreja sempre, eu me sinto bem na igreja. A religião me ajuda muito aqui, me deixa bem, assim, mais solta, me sentindo mais à vontade." (Educadora).

De fato, vários cuidadores comentaram que suas crenças serviam de esteio perante os desafios da jornada de trabalho. A religião nesse contexto parecia ser uma espécie de "força" utilizada para que a instituição funcionasse bem (NEVES et al., 2007). Logo, as narrativas provaram que não existia uma formação específica para eles atuarem nos abrigos:

Eu busco essa capacitação: grupos pra que você possa estar trocando ideias. Mas não que isso exista de fato e, se existe eu não sei. Eu acho que a gente tem que ter um espaço de troca, nisso a gente ainda não avançou e isso fica no negativo. (Assistente Social).

Eu acho que hoje falta muita capacitação para essa equipe que está trabalhando. Têm meninos que vêm de casa, outros que vêm da rua mesmo, outros que vêm da criminalidade. Então, você tem que ter treinamento para lidar com esses meninos. Pois, se houvesse uma capacitação, adiantaria muito mais o trabalho. (Educador).

Essa falta de formação específica acabava sendo compensada pela utilização da MM, sobretudo quando se viam impotentes diante das múltiplas carências dos abrigados, sentindo-se impulsionados a transmitir suas crenças e valores religiosos. A tarefa de educar jovens abrigados estaria ligada à religiosidade, não necessariamente atrelada a uma religião específica:

Eu trabalho há muito tempo com crianças e adolescentes, e minha vida toda foi desse jeito. Tem tudo a ver com a minha vida. Eu não me vejo hoje fazendo outra coisa. Tenho muita fé em Deus e faço minhas orações. A gente faz um encontro todo ano com os adolescentes [no abrigo]. E, ai, tem um lado místico da coisa. Lá, no domingo, eu que escolho as músicas, enfim, de cantar, fazer oração, eu que faço! Mas nunca fui à igreja, nunca fiz primeira comunhão, não tenho religião, mas acredito em Deus e o lado místico ajuda e muito. (Educador).

Percebeu-se que a capacitação e supervisão eram precárias por parte da rede de assistência social. Mas, isso não impedia o desempenho laboral de muitos, pois a $\mathrm{MM}$ como um fator inerente às suas vidas, era um recurso que os ajudava a enxergar diversas situações sob outra perspectiva. Movidos por seus valores religiosos, geralmente atribuíam a uma intervenção divina os auxílios recebidos no cotidiano:

Olha, sou bem recebida graças a Deus. Deus abre as portas onde quer que eu vá, tanto para mim, quanto para os meninos. É Deus mesmo, porque a gente sabe que pela gente mesmo, a gente nada pode fazer. E eu creio que é Deus, através de mim. Então, graças a Deus, eu consigo! Deus envia como amigas e parceiras para estar nos ajudando a conseguir as coisas para os meninos. (Educadora).

No entanto, como a capacitação/supervisão profissional ainda não foi implementada, a lei, como citada abaixo, está sendo descumprida:

Tal serviço deve contar com equipe técnica qualificada para um trabalho ágil para o diagnóstico da situação, bem como com cuidadores/educadores capacitados para acolher crianças e adolescentes em momento de peculiar situação de vulnerabilidade (BRASIL, 2009, p. 32). 
Portanto, independentemente da orientação religiosa de cada cuidador, caberia ao abrigo desenvolver um trabalho técnico de caráter profissional, levando em conta a subjetividade e as necessidades dos jovens. Assim, competiria ao cuidador, estimular o jovem a descobrir suas afinidades e desbravar seus caminhos, de modo responsável e consciente.

\section{CONSIDERAÇÕES FINAIS}

Através do exposto, foi possível perceber que existe uma necessidade de cuidar de quem cuida. $\mathrm{O}$ cuidador, muitas vezes, se assemelha ao abrigado por ser uma vítima de um sistema perverso. De fato, ele é acometido pelo desânimo, pela angústia, pela falta de suporte da rede de assistência social e, enfim, pela violência silenciosa, definida por Leite et al. (2011) como aquela que viola a dignidade humana e torna-se naturalizada por quem a vivencia e por quem a pratica. Ela surge de modo invisível e não é demonstrada objetivamente, por isso, pode passar despercebida. É uma violência que se sobrepõe as outras formas. Assim, é preciso que haja uma estrutura consistente que dê suporte para que os profissionais realizem um trabalho em torno dos verdadeiros objetivos das UAs, conforme preconizado nas Orientações Técnicas (BRASIL, 2009).

Os valores religiosos, como parte intrínseca da subjetividade desses sujeitos, podem se fazer presentes mesmo havendo qualificação/supervisão, no entanto, existindo esse tipo de suporte, esses valores podem ser relativizados e, em alguns casos, melhor manejados.

Percebe-se que ainda há um longo caminho a percorrer para o cumprimento das leis e normas definidas para a proteção integral de adolescentes. Sabe-se que as diretrizes oficiais a respeito das UAs existem, porém questiona-se em que medida elas têm sido colocadas em prática e, especialmente, como elas poderiam se articular nas redes de educação, saúde e saúde mental.

Em suma, espera-se que com este artigo outros estudos, dentro desta temática, venham a ser estimulados, reduzindo a lacuna entre o que está previsto nos documentos legais e a realidade dos profissionais nos abrigos.

ALVES, D. G.; LEMOS, A. A.; MORAES, M. C. M. B.; HALPERN, E. E.; LEITE, L. C. The professional missionary motivation in the shelters for the youth: problem or solution? Rev. Ter. Ocup. Univ. São Paulo, v. 23, n. 2, p. 137-145, maio/ago. 2012.

\begin{abstract}
The study examines the scope to which missionary motivation is a problem or a solution for the professionals working in the shelters for young people from the municipal network. The work is anchored in the results from a project conducted between 2008 and 2010 in two shelters located in Rio de Janeiro, performing 47 interviews with professionals from different functions. The method used to collect data was the oral history, utilizing a semi-structured guide. Data analysis was based on Communication Theory, abducting categories from the narratives. Through the analysis it was found that a significant number of caregivers showed that their religious beliefs seem to guide their professional performance in the shelters, in order to minimize the psychological distress. In brief, it was found that the missionary motivation of the professionals of the shelters has several meanings, especially for the lack of training and supervision.
\end{abstract}

KEY WORDS: Refuge; Professional practice; Religion; Adolescent, institutionalized; Mental health; Caregivers; Motivation.

\title{
REFERENCIAS
}

ALBERTI, V. Ouvir contar: Textos em história oral. Rio de Janeiro: FGV, 2004.

BOUDON, P. L'abduction et le camp sémiotique. In: BRUNEL, G. (Org.) Le tiers communicationnel. Montreal: Harmattan, 1998.

BRASIL. Lei $n^{\circ} 8.069$, de 13 de julho de 1990. Dispõe sobre o Estatuto da Criança e do Adolescente (ECA). Brasília, DF.
BRASIL. Ministério da Justiça, Secretaria de Direitos Humanos, Conselho Nacional de Defesa da Criança e do Adolescente. (CONANDA), Conselho Nacional de Assistência Social (CNAS). Orientações técnicas para os serviços de acolhimento para crianças e adolescentes, 2009. Disponível em: <http://portal.mj.gov.br/sedh/ conanda/documentos/orienta $\% \mathrm{C} 3 \% \mathrm{~A} 7 \% \mathrm{C} 3 \% \mathrm{~B} 5$ es_acolhimento consulta_publica.pdf $>$. Acesso em 27 abr. 2011. 
ALVES, D. G. et al. A motivação missionária religiosa. Rev. Ter. Ocup. Univ. São Paulo, v. 23, n. 2, p. 137-145, maio/ago. 2012.

CASTEL, R. As metamorfoses da questão social. Petrópolis: Vozes, 1998.

DEJOURS, C. A banalização da injustiça social. Trad. Luiz A. Monjardin. 7. ed. Rio de Janeiro: FGV, 2006.

FERREIRA, M. M.; AMADO, J. Usos e abusos da historia oral. Rio de Janeiro: FGV, 1996.

FIDELIS, S. S. S. Conceito de assistência e assistencialismo. In: SEMINÁRIO NACIONAL ESTADO E POLÍTICAS SOCIAIS NO BRASIL, 2, 2005, Paraná. Anais eletrônicos... Paraná: UNIOESTE, 2005. Disponível em: <http://cac-php.unioeste.br/ projetos/gpps/midia/seminario2/poster/servico_social/pss13.pdf $>$. Acesso em 8 dez. 2011.

LEITE et al. Violência, juventude e saúde mental. Universidade Federal do Rio de Janeiro - UFRJ. Instituto de Psiquiatria - IPUB, 2011. [Relatório final não publicado].

LOTUFO NETO, F. Psiquiatria e religião: a prevalência de transtornos mentais entre ministros religiosos. 1997. $375 \mathrm{f}$. Dissertação (Mestrado Medicina) - Faculdade de Medicina da Universidade de São Paulo, SP, 1997.

LOZANO, J. E. A. Práticas e estilos de pesquisa na história oral contemporânea. In: FERREIRA, M.; AMADO, J. (Orgs.). Usos e abusos da história oral. 8. ed. Rio de Janeiro: FGV, 2006.

NEVES, A. S.; PEREIRA, A. L.; CASTRO, G. B. A religião e a institucionalização infanto-juvenil: um estudo sobre a influência das crenças religiosas no desenvolvimento de crianças e adolescentes abrigados. Horizonte Cientifico, v. 1, p. 1-23, 2007. Disponível em: $<$ http://www.seer.ufu.br/index.php/horizontecientifico/article/ viewFile/3829/2834>. Acesso em 8 de dez 2011.

OMS. Relatório mundial de violência e saúde. Genebra, 2002.

PITTA, A. (Org.). Reabilitação psicossocial no Brasil. São Paulo: Hucitec, 1996.

SARACENO, B. Libertando identidades: Da reabilitação psicossocial à cidadania possível. Belo Horizonte: Te Corá/ Instituto Franco Basaglia, 1999.

SIMÕES NETO, J. P. Assistentes sociais e religião: um estudo Brasil/Inglaterra. São Paulo: Cortez, 2005.

THOMPSON, P. A voz do passado: história oral. Rio de Janeiro: Paz e Terra, 1992.

VALLA, V. V. Redes sociais, poder e saúde à luz das classes populares numa conjuntura de crise. Interface (Botucatu), v. 4, n. 7, ago. 2000. Disponível em: <http://dx.doi.org/10.1590/S141432832000000200004>. Acesso em 25 abr. 2012.

VASCONCELOS, E. M.; et al. A contribuição de Victor Valla ao pensamento da educação popular. Rev. Bras. Educ., Rio de Janeiro, v. 14, n. 42, dez. 2009. Disponível em: <http://dx.doi.org/10.1590/ S1413-24782009000300013>. Acesso em 24 abr. 2012.

Recebido para publicação: 15/02/2012

Aceito para publicação: 29/06/2012 